\title{
Evaluation of the spoilage potential of bacteria isolated from spoiled cooked whole tropical shrimp (Penaeus vannamei) stored under modified atmosphere packaging
}

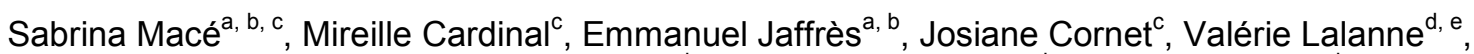 \\ Frédérique Chevalier ${ }^{c}$, Thierry Sérot ${ }^{\mathrm{d}, \mathrm{e}}$, Marie-France Pilet ${ }^{\mathrm{a}, \mathrm{b}}$, Xavier Dousset ${ }^{\mathrm{a}, \mathrm{b}}$, \\ Jean-Jacques Joffraud ${ }^{\mathrm{c}, *}$ \\ a LUNAM Université, ONIRIS, Université Nantes, UMR1014 Secalim, Nantes, F-44307, France \\ b INRA, Nantes, F-44307, France \\ ${ }^{c}$ Ifremer, Laboratoire Science et Technologie de la Biomasse Marine, BP 21105, 44311, Nantes Cedex 3, France \\ ' LUNAM Université, ONIRIS, Université Nantes, UMR 6144 GEPEA, Flavor Unit, F-44307, France \\ ${ }^{\mathrm{e}}$ CNRS, Nantes, F-44307, France
}

*: Corresponding author: Sabrina Macé, tel.: +33 240374284 ; fax: +33240374071;

email address : jean.jacques.joffraud@ifremer.fr

\begin{abstract}
:
The spoilage potential of isolates belonging to five bacterial groups/species (Shewanella baltica, Carnobacterium maltaromaticum, Aeromonas salmonicida, Vibrio sp., "other Gamma-Proteobacteria" [containing one strain of Pseudoalteromonas sp. and one strain of Psychrobacter sp.]) isolated from spoiled cooked and whole tropical shrimp stored under modified atmosphere packaging (MAP) was evaluated by inoculation into ionized cooked and peeled tropical shrimp followed by storage for 32 days at $8^{\circ} \mathrm{C}$. Microbial growth and sensory changes were monitored during the storage period. The major spoilage bacterial isolate groups were $C$. maltaromaticum and S. baltica. In order to characterize their spoilage potential further and to study the effect of their interactions, each of these two specific spoilage organisms (SSO) and one mixed-culture, C. maltaromaticum/S. baltica, were tested using a combination of complementary methods: molecular (PCR-TTGE), sensory, chemical, and conventional microbiological analyses. It was concluded that, in the mixed-culture-inoculated samples, both species groups imposed their spoilage characteristics.
\end{abstract}

\section{Highlights}

Spoilage potential of 5 bacterial groups isolated from spoiled cooked whole shrimp. Specific spoilage organisms were identified among these bacterial groups. Characterization of spoilage potential and bacterial interactions of 2 dominant spoilers. In co-culture, each bacterial group imposed its spoilage characteristics.

Keywords : Spoilage potential ; bacterial interaction ; Specific Spoilage Organism ; cooked tropical shrimp ; volatile compounds 


\section{Introduction}

Prawn and shrimp are the most important products from aquaculture: more than 3.7 million tons were produced in 2010 with a value of more than 16 billion US dollars. Moreover, Penaeus vannamei, also called white leg shrimp, is the species most reared with about 2.7 million tons in 2010 representing 11 billion US dollars on its own (FAO Fisheries Statistics 2012). The current market trend is for the processing of value-added products like cooked shrimp, which is very popular and widely sold in supermarkets as a chilled ready-toeat product under modified atmosphere packaging (MAP). Shrimp quality is essential to maintain not only product value but also the reputation of the farmer, processor and country (Bari et al., 2011).

\section{The spoilage bacterial species of a packaged product depend on its endogenous} microbiota, the processing undergone, the type of packaging (MAP, vacuum, aerobic, etc.) and storage temperature.

While Nordic shrimp (Pandalus borealis) are cooked directly after catching and then frozen (sometimes after being peeled), tropical shrimp (Penaeus sp.) are generally frozen immediately after catching and sold to the processor (Leroi and Joffraud, 2011). It has been known for a long time that processing practices influence microbial count and shrimp microbiota composition. Cooking is the major step to reduce shrimp microbial load but peeling and brining lead to a recontamination dominated by Gram-positive bacteria (Harrison and Lee, 1968). Gram-positive bacteria such as lactic acid bacteria (Carnobacterium sp, Enterococcus sp., etc.) and Brochothrix thermosphacta have been identified as the major spoilage flora of MAP brined and drained cooked shrimp and non-drained MAP cooked peeled shrimp (Dalgaard et al., 2003; Mejlholm et al., 2005; Jaffrès et al., 2009). At the onset of spoilage, the product contains some bacteria that are involved in spoilage, the so-called specific spoilage organisms ( $\mathrm{SSO}$ ), and others that grow without 
causing unpleasant changes. To identify the SSO among the bacterial groups present at the time of spoilage, the impact of bacterial isolates on the chemical and sensory characteristics obtained on inoculated products should be compared to those of naturally spoiled products. These experiments enable the spoilage potential of microorganisms to be determined, i.e. their ability to produce metabolites resulting in off-odours or off-flavours (Gram et al., 2002; Dalgaard, 2006).

Enhancing our knowledge of the SSO for specific seafood products will lead to the development of better detection methods, shelf-life predictions and preservation techniques, thereby reducing losses due to spoilage and improving seafood quality (Dalgaard, 2000). Several studies have focused on MAP cooked and peeled tropical shrimp spoilage or MAP brined and drained shrimp spoilage (Dalgaard, 1995; Dalgaard et al., 2003; Mejlholm et al., 2005; Laursen et al., 2006; Jaffrès et al., 2009; Noseda et al., 2010; Jaffrès et al., 2011; Noseda et al., 2012) but this present study is the first to investigate the spoilage potential of bacteria isolated from whole tropical shrimp.

Our aim was to identify the SSO dominating MAP stored cooked whole tropical shrimp (Penaeus vannamei) and to highlight the interactions between these species. The ability to spoil was investigated for different bacterial groups previously isolated from whole spoiled cooked tropical shrimp; and then the spoilage potential of the strongest spoiling bacterial isolate groups was further characterized.

\section{Materials and Methods}

This study was conducted in two steps. In the first step, five different bacterial groups previously isolated from spoiled whole tropical shrimp were inoculated in a shrimp model 
system by monitoring bacterial and sensory changes throughout the storage period. In the second step, to investigate the interaction among spoilage bacteria, binary cultures combining the two main spoilage bacterial isolates were inoculated into the shrimp model system and characterized by molecular (PCR-TTGE), sensory, chemical, and conventional microbiological analyses.

\subsection{Bacterial isolates}

All isolates tested were previously isolated from four different batches of spoiled cooked whole tropical shrimp obtained from a local plant and packaged under MAP (50\% $\mathrm{CO}_{2} / 50 \% \mathrm{~N}_{2}$ ) and stored according to the shelf-life validation protocol adopted by the company ( 8 days at $2^{\circ} \mathrm{C}$ then $6-8$ days at $8^{\circ} \mathrm{C}$ ). All isolates were identified by $16 \mathrm{~S}$ rRNA gene partial sequencing (700 bp) and found to belong to different genera or species distributed in

five different bacterial groups: Shewanella baltica, C. maltaromaticum, Aeromonas salmonicida, Vibrio sp., "other Gamma-Proteobacteria” (containing one strain of Pseudoalteromonas sp. and one strain of Psychrobacter sp.). Each group was represented by 2 to 6 isolates of the same species depending on the group (except for the "other GammaProteobacteria" group which was composed of two different species) (Table 1).

\subsection{Challenge tests}

Cooked and peeled tropical shrimp from Colombia (South America) (about $7 \mathrm{~kg}$ ) were cooked by the manufacturer and directly transported to the laboratory. They were packaged under vacuum in $1 \mathrm{~kg}$ bags, frozen at $-80^{\circ} \mathrm{C}$ then sterilized and thawed before the experiment as described by Macé et al (2013). Isolates were pre-cultured individually in brain heart infusion broth (BHI) (Difco Laboratories, Detroit, MI, USA) at $20^{\circ} \mathrm{C}$ until their maximal concentration (7-9 $\left.\log \left(\mathrm{CFU} \mathrm{g} \mathrm{g}^{-1}\right)\right)$ was reached (1-3 d). Cultures of several isolates belonging 
124

125

126

127

128

129

130

131

132

133

134

135

136

137

to the same species were pooled in a sterile vial and diluted in sterile peptone water $(0.85 \%$

$\mathrm{NaCl}$ and $0.1 \%$ peptone), in order to achieve an inoculation mixture containing $4 \log$

$\left(\mathrm{CFU} \cdot \mathrm{ml}^{-1}\right)$. Each inoculation mixture $(36 \mathrm{~mL})$ was sprayed onto a batch of approximately 1.2 $\mathrm{kg}$ of the shrimp model system placed in a laminar flow hood to reach an inoculated level of about $3 \log \left(\mathrm{CFU} \cdot \mathrm{g}^{-1}\right)$. A control was prepared by inoculating the ionized shrimp matrix with sterile water. Each batch of inoculated shrimp and the non-inoculated control were placed in 5 plastic trays, each containing $\sim 240 \mathrm{~g}$ portions (one for each analysis date), and packaged under modified atmosphere $\left(50 \% \mathrm{CO}_{2}\right.$ and $\left.50 \% \mathrm{~N}_{2}\right)$ using a Multivac T 200 machine (Hagenmüller, Wolfertschwenden, Germany) and a low gas permeability film (low density polyethylene, LDPE, LINPAC Plastics, permeability: $\mathrm{O}_{2}<5 \mathrm{~cm}^{3} / \mathrm{m}^{2} .24$ h.bar, $\mathrm{CO}_{2}<25$ $\mathrm{cm}^{3} / \mathrm{m}^{2} .24$ h.bar). All batches of inoculated shrimp and the control were stored at $8^{\circ} \mathrm{C}$ for 32 days. Sensory and chemical analyses were carried out after 1, 8, 15, 26 and 32 days.

Microbiological analyses were performed for up to 15 days to verify that all the groups were well implanted on the matrix.

For the next stage (named further characterization of spoilage potential), two isolate groups determined as being the main spoilers by the preliminary characterization step were inoculated singly or in co-cultures. Cultures were inoculated as previously described on the pauci-microbial shrimp model system to achieve initial levels of $3 \log \left(\mathrm{CFU} \cdot \mathrm{g}^{-1}\right)$. A noninoculated control was also prepared. Each different batch of shrimp and the control were divided into 18 plastic trays (around 200 g portions) and packaged as described before. All batches were stored at $8^{\circ} \mathrm{C}$ for 18 days. After $1,4,8,11,15$ and 18 days, samples were subjected to sensory, chemical and microbiological analyses.

\subsection{Enumeration of inoculated isolates}


At each sampling date of the preliminary characterization, one tray of the different batches was used for microbiological count using Brain Heart Infusion Agar medium (BHI) as described by Macé et al (2013).

For further characterization of the spoilage potential, three trays of the different batches were used for microbiological analysis at each sampling date. From each package, a $10 \mathrm{~g}$ portion was aseptically weighed and the three portions were pooled, treated and enumerated as described previously on Brain Heart Infusion Agar medium and pour-plated on Iron Agar (IA). For co-cultured groups, the species were distinguished on IA plates by their morphological and coloration differences: S. baltica, which is an $\mathrm{H}_{2} \mathrm{~S}$-producing bacterium, produces black colonies on IA.

\subsection{Sensory analysis}

Sessions were performed in individual partitioned booths, as described in the procedure NF V-09-105 (AFNOR, 1987), equipped with a computerized system (Fizz, Biosystèmes, Couternon, France). All the samples were frozen after microbiological analysis and kept frozen at $-80^{\circ} \mathrm{C}$ until sensory evaluation. An experimental design was constructed for the sensory sessions in order to balance for contrast effects (bacterial groups and time of storage). Principal component analysis (PCA) with standardization was performed on the means of the scores for each sensory descriptor and spoilage intensity for further characterization. Multivariate data processing was carried out with Uniwin Plus 6.1 software (Sigma Plus).

Sensory analysis was carried out by an internal panel of IFREMER, experienced in the evaluation of seafood, especially of tropical shrimp (Jaffrès et al., 2009 and 2011). For each assessor, portions of 3-4 shrimp were placed in plastic containers with lids to keep the odours intact. 
Nine trained panellists, selected according to their sensory capacities, participated in

174

175

176

177

178

the preliminary characterization of spoilage potential. One tray per batch was opened.

Panellists scored the spoilage level on a continuous scale from 0 to 10 and chose two main characteristic odours from the following descriptors selected during preliminary sessions: rice, crustacean, surimi, marine/iodine, milky, butter/caramel, floor cloth, pyrrolidine, dirt/mould, amine, acid, sour/fermented, feet/cheese, cabbage/sulphur, nothing. The products were considered strongly spoiled when they reached a score of 6 .

For further characterization of the spoilage potential, three trays per batch were used and 12 trained panellists participated in this experiment. A quantitative descriptive analysis (QDA) described by (Stone and Sidel, 2004) was used to determine the sensory profile (ISO, 2003) of each batch inoculated with each species and co-cultured species. First, panellists had to score the spoilage level on a continuous scale from 0 to 10 and then using the following appropriate odour descriptors considered pertinent during the previous step: overall intensity, rice, crustacean, milky, butter/caramel, pyrrolidine, amine, acid/ vinegar, sour/fermented, feet/cheese, cabbage/sulphur.

A two-way analysis of variance was applied to the panellists' scores for spoilage intensity with products (strain) and panellists as independent factors. Significant differences between means were determined using Duncan's multiple range test $(\mathrm{p}<0.05)($ Fizz software).

\subsection{Chemical analysis}

Total Volatile Basic Nitrogen (TVBN) measurements were only performed in the further characterization stage. At each sampling date, $150 \mathrm{~g}$ of inoculated cooked and peeled tropical shrimp were analysed as described by Macé et al (2013). 


\subsection{Analysis of volatile compounds}

During further characterization of spoilage potential, at day 1 and day 18 , volatile compounds produced by the non-inoculated control sample and the $S$. baltica-inoculated sample were analysed using a gas chromatography device, model GC 7890A, Agilent (Agilent Technologies, Santa Clara, USA) coupled with a mass spectrometer 5975 C VL (Agilent) and flame ionization detector after solid-phase microextraction (SPME/GC-MSFID). The extraction and injection processes were performed automatically using an autosampler MPS 2 (Gerstel, Mülheim, Germany). Briefly, volatile compounds of 5-g portions of shrimp sample were analysed as described by Jaffrès et al (2011) with some adjustments: vial heating for $40 \mathrm{~min}$ (instead of $50 \mathrm{~min}$ ), Stable Flex ${ }^{\mathrm{TM}}$ exposure in the headspace of the vial for $30 \mathrm{~min}$ (instead of $25 \mathrm{~min}$ ) and maximum oven temperature of $240^{\circ} \mathrm{C}$ (instead of $280^{\circ} \mathrm{C}$ ).

Compounds were identified by comparison of mass spectra with a reference database (Wiley 6.0), and by comparison of mass spectra and linear retention indexes (LRI) with those of standards injected in the same conditions.

Mean values of sample peak areas were compared by analysis of variance to identify specific spoilage volatile compounds. ANOVA processing was performed with Statgraphics Plus 5.1 software (Statistical Graphics Corp.). Data were reported as log (peak area/g) for each specific compound detected.

\subsection{Temporal Temperature Gel Electrophoresis (TTGE) analysis on co-cultured inoculated samples}

The suspension prepared for bacteriological analysis was used to obtain molecular fingerprints from the shrimp matrix inoculated with co-culture isolate groups. Bacterial DNA extraction was performed as described previously by Jaffrès et al., 2009. 
224

225

226

227

228

229

230

231

232

233

234

235

236

237

238

239

240

241

242

243

244

245

246

247

described previously by Jaffrès et al., 2009. Standardization, analysis and comparison of TTGE fingerprints were monitored using BioNumerics Software, version 6.0 (Applied Maths NV, Sint-Martens-Latem, Belgium) as described by Macé et al., 2012.

\section{Results}

\subsection{Preliminary characterization of spoilage potential}

\subsubsection{Enumeration of the different bacterial groups}

Figure 1 shows the mean growth pattern of the five different bacterial groups. The ionized control was little contaminated, about $0.7 \log$ CFU.g ${ }^{-1}$ at inoculation time, and thus considered a pauci-microbial matrix. The initial counts of the inoculated samples were between 2.6 to $4.2\left(\mathrm{CFU}_{\mathrm{g}} \mathrm{g}^{-1}\right)$. Growth of bacterial groups reached between 5.4 and $8.5 \mathrm{log}$ $\left(\mathrm{CFU} . \mathrm{g}^{-1}\right)$ after 8 days of storage. At 15 days of storage, all the bacterial groups rose to levels ranging between 6.3 (“other Gamma-Proteobacteria" group) and $9.9 \log \left(\mathrm{CFU} . \mathrm{g}^{-1}\right)(C$. maltaromaticum) and were considered well implanted.

\subsubsection{Sensory characteristics of inoculated cooked tropical shrimp}

Figure 2 presents the spoilage kinetics of the different inoculated samples. Although the results are not always significantly different due to differences between panellist responses, a trend can be observed for each sample. After 1 day of storage, all samples were considered non-spoiled, with a score of about 2 out of 10 (Figure 2). At day 8, the spoilage samples had increased and samples inoculated with two bacterial groups, $C$. maltaromaticum or A. salmonicida, were considered strongly spoiled with a grade above 6 .

After 15 days, two samples inoculated with C. maltaromaticum or S. baltica were assessed as strongly spoiled with a score of around 7 or 8 , respectively. Those inoculated with 
248

249

250

251

252

253

254

255

256

257

258

259

260

261

262

263

264

265

266

267

268

269

270

271

272

A. salmonicida appeared less spoiled until the end of storage with scores decreasing from 5.5 (15 days) to 4.6 (26 days) and finally to 4.3 (32 days). Vibrio sp.- or "other Gamma-

Proteobacteria"-inoculated samples remained lightly spoiled with a score between 4 and 5 .

The ionized control sample was not considered spoiled throughout the storage period. Its spoilage score reached 3 at the end of storage, probably due to the remaining endogenous bacteria.

After 8 days of storage, the inoculated batches exhibited different typical characteristic odours. For each bacterial group, the main sample off-odours, as quoted by at least 3 panellists, are listed in Table 2. Sour and cabbage/sulphur were determined as typical odours for S. baltica-inoculated samples during all the storage, while sour and feet/cheese characterized C. maltaromaticum-inoculated spoiled samples. The main odours of $A$. salmonicida-inoculated samples changed from butter and pyrrolidine during the first 8 days of storage to a mix of several odours like sour, cabbage/sulphur, butter, amine, feet/cheese at the end. Crustacean odour, linked to fresh shrimp, was found at first on Vibrio sp.-inoculated samples but then sour, acid and cabbage/sulphur odours prevailed. After 15 days of storage, "other Gamma-Proteobacteria"-inoculated samples displayed feet/cheese odours, which were replaced by a sour odour at the end. Throughout storage, non-inoculated sample displayed a mix of typical fresh (crustacean, rice, nothing) and spoiled shrimp odours (cabbage/sulphur, sour/fermented, acid, feet/cheese).

Bacterial isolates belonging to C. maltaromaticum and S. baltica were responsible for the strongest spoilage odours detected and were considered to be the main spoilage bacteria in the product throughout storage. Hence, their spoilage potential was subjected to further characterization. It can be noticed that, despite reaching grade 6 at day 8, A. salmonicida was not considered a strong spoiler because its spoilage intensity decreased after 8 days of storage. 


\subsection{Further characterization of spoilage potential}

\subsubsection{Spoilage potential of single-species groups}

Figure 4 shows the spoilage kinetic trends of the inoculated samples. The ionized control presented weak bacterial counts, from 2.3 to $3.7 \log \left(\mathrm{CFU} . \mathrm{g}^{-1}\right)$, throughout the storage (Figure 3) and was thus considered a pauci-microbial matrix. The control sample was scored "non-spoiled" during the entire storage period (18 days) with scores between 0 and 2 (Figure 4).

The principal component analysis (PCA) presented in Figure 5 was performed on the mean scores of profiling tests and summarizes the evolution of the main odour characteristics.

The simultaneous projection of samples and sensory descriptors is shown on the first 1-2 plane. The first axis (64.4\% of the information) enables the spoilage level of each sample to be visualized. It divides the typical odours of freshness of non-spoiled products, on the left, from the spoiled samples, on the right, around typical off-odours of cooked tropical shrimp with sour, feet/cheese, etc. The second axis, representing $16.5 \%$ of the information, is mainly created by butter, sulphur and pyrrolidine descriptors and enables the visualization of samples presenting the same spoilage characteristics. All the control samples, from day 1 to day 18 , are on the left part of this Figure, surrounding the unspoiled inoculated samples and presenting crustacean and rice odours characteristic of freshness.

The results of viable counts of samples inoculated with the two different bacterial isolate groups and their co-culture are shown in Figure 3. C. maltaromaticum counts were initially $3.4 \log \left(\mathrm{CFU} . \mathrm{g}^{-1}\right)$ then rapid growth was observed reaching more than $6.5 \mathrm{log}$ $\left(\right.$ CFU.g $\left.{ }^{-1}\right)$ after 4 days of storage. At 8 days of storage, $C$. maltaromaticum concentration was $8.9 \log \left(\mathrm{CFU} . \mathrm{g}^{-1}\right)$ and increased to $9.6 \log \left(\mathrm{CFU}_{\mathrm{g}} \mathrm{g}^{-1}\right)$ at the end of storage. The sample spoilage score rose to 5.7 after 8 days of storage to reach a maximum of about 6.6 after 11 days before decreasing slowly to 5.4 at the end of storage (Figure 4). These samples exhibited 
298

299

300

301

302

303

304

305

306

307

308

309

310

311

312

313

314

315

316

317

318

319

320

321

322

mainly sour, acid and feet/cheese odours after 11, 15 and 18 days of storage (Figure 5) while the sample at 8 days displayed a butter odour. TVBN production was induced by $C$. maltaromaticum and reached $60 \mathrm{mg}-\mathrm{N} 100 \mathrm{~g}^{-1}$ at the end of storage (Figure 6).

S. baltica were inoculated at around $2 \log \left(\right.$ CFU.g $\left.{ }^{-1}\right)$ (Figure 3). A slow growth was observed, reaching about $5.6 \log \left(\mathrm{CFU} \cdot \mathrm{g}^{-1}\right)$ after 8 days of storage and achieved progressively a maximum of $8.7\left(\mathrm{CFU} \cdot \mathrm{g}^{-1}\right)$ at the end of storage. The samples were considered unspoiled until the $8^{\text {th }}$ day of storage, lightly spoiled after the $11^{\text {th }}$ day with a score of 4.3 and almost strongly spoiled with a score of 5.9 after 18 days of storage (Figure 4). After 11 days of storage, these samples displayed sulphur, pyrrolidine and amine spoilage odours (Figure 5). An increase in TVBN production was observed with a maximal level of $50 \mathrm{mg}-\mathrm{N} 100 \mathrm{~g}^{-1}$ at the end of storage (Figure 6).

The S. baltica group, considered one of the spoiling groups tested here, was included in the volatile compound study using SPME/GC-MS-FID. Approximately 40 compounds were identified in the sample tested. Statistical treatment ( $\mathrm{p}$ value $<0.05$ ) was used to compare the non-inoculated control sample stored for 1 and 18 days, the newly S. balticainoculated sample (1 day of storage) and spoiled sample (18 days). Hence, 18 compounds exhibiting a specific behaviour on the spoiled sample tested were determined (Table 3). Among them, 14 were only detected in samples spoiled by S. baltica: butanol, isoamylalcohol, 1-hexanol, 2-hexenal, acetic acid, isovaleric acid, isobutyric acid, 2propanone (acetone), 2-heptanone, 3-hydroxybutanone (acetoin), 2-nonanone, 2-decanone, methyl-P-tert-butyl phenyl acetate and p-menthane. 1-pentanol (amylalcohol), 1-penten-3-ol and methyl mercaptan production increased slightly in S. baltica-inoculated samples after 18 days of storage compared to the three other samples $(\mathrm{p}<0.05)$. Ethanol presented a small decrease in the $S$. baltica spoiled samples $(\mathrm{p}<0.05)$. 


\subsubsection{Spoilage potential of mixed-species group}

In the presence of S. baltica, C. maltaromaticum presented quite similar bacterial growth compared to the monoculture (except that its inoculation level was lower). In the presence of $C$. maltaromaticum, S. baltica growth was faster and reached about $7.4 \log$ $\left(\right.$ CFU.g $\left.{ }^{-1}\right)$ after 8 days of storage (Figure 3).

Co-culture samples gave the maximum production of TVBN with about $63 \mathrm{mg}-\mathrm{N} 100$ $\mathrm{g}^{-1}$ observed among all the samples tested in this study (Figure 6).

These samples presented the same spoilage behaviour as $C$. maltaromaticum singlespecies samples and were strongly spoiled at the same time (Figure 4). However, their characteristic odours were closer to those of $S$. baltica-inoculated samples with sulphur, amine and a stronger pyrrolidine odour, except for the co-inoculated sample at day 8 which presented a butter odour (Figure 5).

TTGE analysis enabled microbiota dynamics to be visualized by examining fingerprints of the dominant bacterial groups evolving during storage in co-culture-inoculated samples. In order to analyse the TTGE patterns, fingerprints of the different samples were compared with those of pure isolates involved in each bacterial group: C. maltaromaticum, and S. baltica. In fact, these species are present in different seafood products and some of them have already been studied by PCR-TTGE in previous studies (Macé et al., 2012; Macé et al., 2013). Concerning S. baltica, two pure isolates were used for assignation because their TTGE profiles present several different bands.

C. maltaromaticum and S. baltica co-culture TTGE patterns are shown in Figure 7.

Patterns of isolates visualized in any of the samples after 1 and 4 days of storage did not correspond to pure profiles of isolates. They are assumed to be endogenous bacteria present on the ionized sample (data not shown). By comparing band migration positions, $C$. maltaromaticum was assigned in 5 samples after 4, 8, 11, 15 and 18 days of storage. Typical 
348

349

350

351

352

353

354

355

356

357

358

359

360

361

362

363

364

365

366

367

368

369

370

371

372

S. baltica bands were visualized in 4 samples, from 8 days until the end of storage but presented only faint bands

\section{Discussion}

Contrary to the description of Gram-positive bacteria as the main spoilage organisms in previous studies, here, cooked whole tropical shrimp spoilage microbiota were found to be dominated by $S$. baltica in association with C. maltaromaticum (data not shown). It has already been demonstrated that Gram-negative bacteria dominate shrimp microbiota after cooking but before peeling (Harrison and Lee, 1968). Gram-negative bacteria are also a major part of raw shrimp spoilage bacteria stored in ice (Jeyasekaran et al., 2006). A recent study concerning MAP cooked and peeled North Atlantic grey shrimp (Crangon crangon) also described $\mathrm{H}_{2} \mathrm{~S}$-producing bacteria and LAB as dominant flora at the end of storage (Noseda et al., 2012).

All bacterial groups present on the spoiled product were not involved in spoilage (Dalgaard, 2000; Gram et al., 2002). For example, in the preliminary characterization of spoilage potential, only two of the five bacterial groups tested were considered to be strong spoilers, namely: C. maltaromaticum and S. baltica after 8 and 15 days of storage, respectively, at $8^{\circ} \mathrm{C}$. A mix of several isolates per species was used to avoid an isolate effect commonly described for spoilage bacteria (Joffraud et al., 2006; Laursen et al., 2006).

For each single-species group tested in the preliminary and further characterization steps, the spoilage of the inoculated sample started after a certain bacterial concentration level corresponding to the stationary phase according to the SSO concept (Dalgaard, 2000). $C$. maltaromaticum-inoculated samples were spoiled when bacterial counts reached between 8 and $9 \log \left(\mathrm{CFU} \cdot \mathrm{g}^{-1}\right)$. The same bacterial level was observed for cooked and peeled tropical shrimp and salmon spoilage by C. maltaromaticum (Jaffrès et al., 2011; Macé et al., 2013). It 
373

374

375

376

377

378

379

380

381

382

383

384

385

386

387

388

389

390

391

392

393

394

395

396

was determined that high concentrations of S. putrefaciens $\left(8-9 \log \left(\mathrm{CFU} \cdot \mathrm{g}^{-1}\right)\right)$ are required to produce off-odours in seafood (Dalgaard, 1995). In the present study, the same bacterial level was observed in samples spoiled by $S$. baltica.

Some C. maltaromaticum strains present spoilage ability on several seafood products, notably cooked shrimp (Laursen et al., 2005; Mejlholm et al., 2005; Laursen et al., 2006;

Leisner et al., 2007; Jaffrès et al., 2011). Sour, feet/cheese, milky, and/or butter odour were noticed in this study for $C$. maltaromaticum-inoculated spoiled samples but these off-odours were also associated with this species during characterization of cooked and peeled tropical shrimp, raw salmon and cold-smoked salmon spoilage (Joffraud et al., 2001; Jaffrès et al., 2011; Macé et al., 2013). Laursen et al.(2006) linked C. maltaromaticum off-odours to malty, nutty, nauseous sweet odours but also to sour odour on an inoculated cooked shrimp sample.

S. putrefaciens and S. putrefaciens-like bacteria, such as S. baltica, play an important role in seafood spoilage and produce spoilage compounds like TMA and sulphur compounds like $\mathrm{H}_{2} \mathrm{~S}$ which lead to fishy and sulphur odours. They are able to develop on ice-stored products like seafood (Papadopoulos et al., 2003; Vogel et al., 2005; Dalgaard, 2006) and have also been identified as part of the spoilage microbiota of MAP seafood (Hovda et al., 2007; Tryfinopoulou et al., 2007). The production of sulphur compounds could be linked to the typical cabbage/sulphur odours of S. baltica spoiled samples.

The spoilage potential of these two bacterial isolate groups was thus studied singly or in combination using a multi-parameter approach to investigate any interaction between the species in terms of growth, chemical changes and sensory evolution. This type of approach has been used in several works on raw and cold-smoked salmon (Jorgensen et al., 2000; Joffraud et al., 2006; Macé et al., 2013) and on shrimp (Mejlholm et al., 2005; Laursen et al., 2006). 
Few growth differences were found between bacteria in co-culture and alone in the

398

399

400

401

402

403

404

405

406

407

408

409

410

411

412

413

414

415

416

417

421

matrix. In the presence of $S$. baltica, $C$. maltaromaticum was not inhibited and still grew quite quickly on cooked tropical shrimp, reaching about $9 \log \left(\mathrm{CFU} \cdot \mathrm{g}^{-1}\right)$ in 8 days. In other cooked shrimp challenge tests, it has already been observed that $C$. maltaromaticum grows to high concentrations after about 10 days of storage, alone or in co-culture with Brochothrix thermosphacta (Mejlholm et al., 2005; Laursen et al., 2006; Jaffrès et al., 2011). TTGE analyses enabled the dominant group evolution to be visualized during storage. Fingerprints of co-inoculated samples displayed the dominance of the $C$. maltaromaticum isolate group and its faster implantation in the matrix.

S. baltica growth seemed to be accelerated by the presence of $C$. maltaromaticum with a bacterial concentration of about $7.4 \log \left(\mathrm{CFU}_{\mathrm{g}} \mathrm{g}^{-1}\right)$ in co-culture compared to $5.6 \log \left(\mathrm{CFU} \cdot \mathrm{g}^{-}\right.$ ${ }^{1}$ ) in mono-culture after 8 days. This could be due to metabiosis behaviour between the two species favouring S. baltica growth (Gram et al., 2002).

The spoilage kinetics of co-inoculated samples corresponded to C. maltaromaticum samples behaviour whereas their off-odours were closer to those of $S$. baltica samples with a stronger pyrrolidine odour. The increase in intensity of this odour was perhaps due to an interaction between metabolites produced by the two bacterial groups. The same kind of observation appeared for C. maltaromaticum- and B. thermosphacta-inoculated shrimp samples, where a particular odour was formed only when they were co-cultured (Mejlholm et al., 2005; Laursen et al., 2006). The modification of bacterial metabolism in co-cultures (metabiosis) is frequently involved in spoilage mechanisms (Jorgensen et al., 2000; Gram et al., 2002). For example, Jorgensen et al., (2000) demonstrated that the spoilage activity and biogenic amine production of $H$. alvei was enhanced in the presence of LAB.

During the last few years, several studies have shown a correlation between the release of spoilage volatile compounds and the development of specific microbial species during 
storage of seafood products (Jorgensen et al., 2001; Joffraud et al., 2001; Wierda et al., 2006)

and notably of shrimp (Laursen et al., 2006; Jaffrès et al., 2011; Noseda et al., 2012). Volatile compounds produced by one of the dominant spoilers, S. baltica, were investigated in this study. We chose to focus on isolates of this species because volatile compound production by C. maltaromaticum isolates on cooked tropical shrimp product has already been studied recently (Jaffrès et al., 2011). As several origins are possible for these volatile metabolites, it is difficult to attribute them to a specific pathway but some hypotheses can be made. 3hydroxybutanone is an interesting compound resulting from microorganism glycogen catabolism (Joffraud et al., 2001; Laursen et al., 2006). Acetic acid production during spoilage of shrimp has already been related to microbial growth (Noseda et al., 2012) and it can be produced in different metabolic pathways (Joffraud et al., 2001). Shewanella has been assumed to be involved in acetone production on spoiled shrimp (Noseda et al., 2012).

Sulphur components, such as methyl mercapthan, play an important role in shrimp spoilage (Noseda et al., 2012). Moreover, methyl mercaptan is produced by Shewanella species and results from the breakdown of methionine but it can also be an intermediate product of the metabiosis of dimethylsulphide and dimethyldisulphide (Noseda et al., 2012). In this study, methyl mercaptan production is described in S. baltica spoiled sample and it is the only compound which can be linked to the sulphur/cabbage odour of this sample (Fenaroli, 2001). Methyl mercaptan could be an interesting spoilage marker for MAP cooked whole tropical shrimp, even though the sensory profile of seafood products depends on a combination of different compounds rather than a single one (Laursen et al., 2006; Jaffrès et al., 2011).

\section{Conclusion}

The results of these challenge-test studies show that two isolate groups from five bacterial groups associated with cooked whole tropical shrimp stored under MAP were 
447 determined as fast and strong spoilers: C. maltaromaticum and S. baltica. Their assessment

448 alone or in co-culture, using a multi-parametric approach, demonstrated that $C$.

449 maltaromaticum is one of the SSO of cooked whole tropical shrimp. In fact, this bacterial

450 spoiler was able to cause rapid and strong spoilage. Therefore, this work has also contributed

451 to characterizing the spoilage potential of bacterial species isolates in association and to

452 highlight that interaction between C. maltaromaticum and S. baltica can enhance the intensity

453 of the pyrrolidine odour of a cooked shrimp sample. Moreover, in co-inoculated samples,

454 each species group imposes its characteristics: the spoilage kinetics of C. maltaromaticum and

455 the odours of S. baltica. In order to understand the mechanism involved in these interactions,

456 more detailed investigations are required. However, this work is a first step towards a better

457 comprehension of the natural spoilage of cooked whole tropical shrimp.

\section{Acknowledgements}

460 This study was carried out as part of the MIPROMER programme, managed by Pôle

461 Agronomique Ouest (PAO). Sabrina Macé's PhD thesis is financially supported by the

462 regions of Bretagne and Pays de la Loire and by Oniris (Nantes). We thank STBM department

463 member Sandrine Bruzac for chemical analyses and the sensory panel for their contribution.

464

465 References

466

467 AFNOR. (1987). Normalisation française. Analyse sensorielle. Directives générales pour

468 l'implantation de locaux destinés à l'analyse sensorielle V09-105. 
470

471

472

473

474

475

476

477

478

479

480

481

482

483

484

485

486

487

488

489

490

491

492

Bari, L., Yeasmin, S., Kawamoto, S., \&Isshiki, K. (2011). Microbiological safety and quality

of processed shrimp and fishes In: R., M.D.R., (Ed.), Aquaculture microbiology and

biotechnology, vol. 2. Science Pubisher, New Hampshire. 74-100.

Dalgaard, P. (1995). Qualitative and quantitative characterization of spoilage bacteria from packed fish. International Journal of Food Microbiology 26, 319-333.

Dalgaard, P. (2000). Fresh and lightly preserved seafood In: Man, C.D., Jones, A.A., (Eds.),

Shelf life Evaluation of Foods (2nd edition). Aspen Publishing Inc, Maryland, USA. 110-139.

Dalgaard, P., Vancanneyt, M., Euras Vilalta, N., Swings, J., Fruekilde, P., Leisner, J.J. 2003.

Identification of lactic acid bacteria from spoilage associations of cooked and brined shrimps

stored under modified atmosphere between $0^{\circ} \mathrm{C}$ and $25^{\circ} \mathrm{C}$. Journal of Applied Microbiology

94, 80-89

Dalgaard, P. (2006). Microbiology of marine muscle foods. In: Hui, Y.H., (Ed.), Handbook of

Food Science, Technology and Engineering, vol. 1. Taylor \& Francis CRC Press, USA. 53-51

FAO Fisheries Statistics (2012). Global Aquaculture Production 1950-2010 (online query :

http://www.fao.org/fishery/statistics/global-aquaculture-production/query/en).

Fenaroli. 2001. Fenaroli's Handbook of Flavor Ingredients 4th Edition. CRC Press, Orlando, Florida, USA ed. 
493

494

495

496

497

498

499

500

501

502

503

504

505

506

507

508

509

510

511

512

513

514

515

516

Gram, L., Ravn, L., Rasch, M., Bruhn, J.B., Christensen, A.B., \&Givskov, M. (2002). Food

spoilage-interactions between food spoilage bacteria. International Journal of Food

Microbiology 78, 79-97.

Harrison, J.M.\& Lee, J.S. (1968). Microbiological evaluation of pacific shrimp processing. Applied Microbiology 18, 188-192.

Hovda, M.B., Sivertsvik, M., Lunestad, B.T., Lorentzen, G.,\& Rosnes, J.T. (2007).

Characterisation of the dominant bacterial population in modified atmosphere packaged farmed halibut (Hippoglossus hippoglossus) based on 16S rDNA-DGGE. Food Microbiology $24,362-371$.

ISO, I.O.f.S. (2003). Sensory analysis, methodology. General guidance for establishing a sensory profile, ISO 13299, Geneva, Switzerland

Jaffrès, E., Lalanne, V., Macé, S., Cornet, J., Cardinal, M., Sérot, T., Dousset, X., \&Joffraud, J.J. (2011). Sensory characteristics of spoilage and volatile compounds associated with bacteria isolated from cooked and peeled tropical shrimps using SPME-GC-MS analysis. International Journal of Food Microbiology 147, 195-202.

Jaffrès, E., Sohier, D., Leroi, F., Pilet, M.F., Prévost, H., Joffraud, J.J.,\&Dousset, X. (2009).

Study of the bacterial ecosystem in tropical cooked and peeled shrimps using a polyphasic approach. International Journal of Food Microbiology 131, 20-29. 
517 Jeyasekaran, G., Ganesan, P., Anandaraj, R., Jeya Shakila, R., \&Sukumar, D. (2006).

518 Quantitative and qualitative studies on the bacteriological quality of Indian white shrimp

519 (Penaeus indicus) stored in dry ice. Food Microbiology 23, 526-533.

520

521

Joffraud, J.J., Cardinal, M., Cornet, J., Chasles, J.S., Leon, S., Gigout, F.,\& Leroi, F. (2006).

522

Effect of bacterial interactions on the spoilage of cold-smoked salmon. International Journal of Food Microbiology 112, 51-61.

524

Joffraud, J.J., Leroi, F., Roy, C.,\& Berdagué, J.L. (2001). Characterisation of volatile

compounds produced by bacteria isolated from the spoilage flora of cold-smoked salmon.

527

International Journal of Food Microbiology 66, 175-184.

528

Jorgensen, L.V., Huss, H.H., \&Dalgaard, P. (2000). The effect of biogenic amine production by single bacterial cultures and metabiosis on cold-smoked salmon. Journal of Applied Microbiology 89, 920-934.

532

Jorgensen, L.V., Huss, H.H.,\& Dalgaard, P. (2001). Significance of volatils coumpound produced by spoilage bacteria in vacuum-packed cold smoked salmon (Salmo salar) analyzed by GC-MS and multivariate regression. Journal of Food Chemistry 49, 2376-2381.

Laursen, B.G., Bay, L., Cleenwerck, I., Vancanneyt, M., Swings, J., Dalgaard, P.,\& Leisner,

J.J. (2005). Carnobacterium divergens and Carnobacterium maltaromaticum as spoilers or protective cultures in meat and seafood: phenotypic and genotypic characterization.

541 Systematic and Applied Microbiology 28, 151-164. 
543 Laursen, B.G., Leisner, J.J.,\& Dalgaard, P. (2006). Carnobacterium species: effect of

544 metabolic activity and interaction with Brochothrix thermosphacta on sensory characteristics

545 of modified atmosphere packed shrimp. Journal of Agricultural and Food Chemistry 54, $546 \quad 3604-3611$.

547

548 Leisner, J.J., Laursen, B.G., Prévost, H., Drider, D.,\& Dalgaard, P. (2007). Carnobacterium: 549 positive and negative effects in the environment and in foods. FEMS Microbiology Reviews $550 \quad 31,592-613$.

551

552

Leroi, F.\& Joffraud, J.-J. (2011). Microbial degradation of seafood. In: R., M.D.R., (Ed.),

553

554

555

556

557

558

559

560

561

562

563

564

Aquaculture microbiology and biotechnology, vol. 2. Science Pubisher, New Hampshire. 4772.

Macé, S., Cornet, J., Chevalier, F., Cardinal, M., Pilet, M.-F., Dousset, X.,\& Joffraud, J.-J.

(2012). Characterisation of the spoilage microbiota in raw salmon (Salmo salar) steaks stored under vacuum or modified atmosphere packaging combining conventional methods and PCRTTGE. Food Microbiology 30, 164-172.

Macé, S., Joffraud, J.-J., Cardinal, M., Malcheva, M., Cornet, J., Lalanne, V., Chevalier, F., Sérot, T., Pilet, M.-F.,\& Dousset, X. (2013). Evaluation of the spoilage potential of bacteria isolated from spoiled raw salmon (Salmo salar) fillets stored under modified atmosphere packaging. International Journal of Food Microbiology 160, 227-238.

565 
566

567

568

569

570

571

572

573

574

575

576

577

578

579

580

581

582

583

584

585

586

587

588

589

590

Mejlholm, O., Bøknæs, N.,\& Dalgaard, P. (2005). Shelf life and safety aspects of chilled

cooked and peeled shrimps (Pandalus borealis) in modified atmosphere packaging. Journal of Applied Microbiology 99, 66-76.

Noseda, B., Dewulf, J., Goethals, J., Ragaert, P., Van Bree, I., Pauwels, D., Van Langenhove, H.,\& Devlieghere, F. (2010). Effect of Food Matrix and pH on the Volatilization of Bases (TVB) in Packed North Atlantic Gray Shrimp (Crangon crangon): Volatile Bases in MAP Fishery Products. Journal of Agricultural and Food Chemistry 58, 11864-11869.

Noseda, B., Goethals, J., De Smedt, L., Dewulf, J., Samapundo, S., Van Langenhove, H., \&Devlieghere, F. (2012). Effect of $\mathrm{O}_{2}-\mathrm{CO}_{2}$ enriched atmospheres on microbiological growth and volatile metabolite production in packaged cooked peeled gray shrimp (Crangon crangon). International Journal of Food Microbiology 160, 65-75.

Papadopoulos, V., Chouliara, I., Badeka, A., Savvaidis, I.N., \&Kontominas, M.G. (2003).

Effect of gutting on microbiological, chemical, and sensory properties of aquacultured sea bass (Dicentrarchus labrax) stored in ice. Food Microbiology 20, 411-420.

Stone, H.\& Sidel, J.L. (2004). Sensory evaluation practices 3rd edition Elsevier Academic Press, Amsterdam.

Tryfinopoulou, P., Tsakalidou, E., Vancanneyt, M., Hoste, B., Swings, J., \& Nychas, G. J. E. (2007). Diversity of Shewanella population in fish Sparus aurata harvested in the Aegean Sea. Journal of Applied Microbiology, 103, 711-721. 
591 Vogel, B.F., Venkateswaran, K., Satomi, M., \&Gram, L. (2005). Identification of Shewanella

592 baltica as the most important $\mathrm{H}_{2} \mathrm{~S}$-producing species during iced storage of danish marine

593 fish. Applied and Environmental Microbiology 71, 6689-6697.

594

595 Wierda, R.L., Fletcher, G., Xu, L.,\& Dufour, J.P. (2006). Analysis of volatile compounds as

596 spoilage indicators in fresh king salmon (Oncorhynchus tshawytscha) during storage using

597 SPME-GC-MS. Journal of Agricultural and Food Chemistry 54, 8480-8490.

598

599 
Figure 1: Growth of five bacterial groups in MAP cooked tropical shrimp during storage at $8^{\circ} \mathrm{C}$.

Figure 2: Spoilage scores of cooked tropical shrimp inoculated with 5 bacterial groups stored under MAP at $8^{\circ} \mathrm{C}$ for 32 days determined by the sensory panel ( 9 panellists). For each day of storage, analysis of variance with samples and panellists as independent factors, and Duncan's multiple comparison test $(\mathrm{p}<0.05)$ were performed. Different letters indicate significant differences between samples.

Figure 3: Growth of each bacterial group in cooked tropical shrimp during MAP storage at $8^{\circ} \mathrm{C}$ for 18 days: enumeration of C. maltaromaticum and $S$. baltica group alone or in coculture (C. maltaromaticum in the presence of $S$. baltica or $S$. baltica in the presence of $C$. maltaromaticum)

Figure 4: Spoilage level mean scores as determined by the sensory panel (12 panellists) for each of the inoculated cooked shrimp samples (continuous scale from 0 to 10) during storage at $8^{\circ} \mathrm{C}$ for 18 days. For each day of storage, analysis of variance, with samples and panellists as independent factors, and Duncan's multiple comparison test $(\mathrm{p}<0.05)$ were performed. Different letters indicate significant differences between samples. 
Figure 5: Simultaneous representation of inoculated cooked shrimp samples and odour descriptors on planes 1-2 of principal component analysis. Sample nomenclature: C, control samples (non-inoculated); carno, Carnobacterium maltaromaticum; shew, Shewanella baltica; msc, co-culture of $S$. baltica and C. maltaromaticum. Numbers in labels of samples represent time of storage (in days).

Figure 6: Development of total volatile basic nitrogen (TVBN, mg-N $100 \mathrm{~g}^{-1}$ ) in cooked tropical shrimps inoculated with different bacterial groups during MAP storage for 18 days at $8^{\circ} \mathrm{C}$.

Figure 7: Fingerprints and dynamics of co-cultures inoculated on cooked tropical shrimp during storage at $8^{\circ} \mathrm{C}$ for 18 days. Digitized TTGE profiles of 16S rRNA gene V3 regions obtained by PCR amplification from bacterial DNA of 6 samples inoculated with one mixed culture: C. maltaromaticum with S. baltica stored at $8^{\circ} \mathrm{C}$ for 18 days. Lanes D1 to D18 corresponded to samples: day 1 , day 4 , day 8 , day 11 , day 15 , day 18 . Bands "c" were assigned as C. maltaromaticum and bands "s1-s3" as S. baltica by comparison with pure isolate profiles. Bands * are assumed to be endogenous bacteria. 
Table 1. List of bacterial isolates inoculated on ionized cooked tropical shrimp during challenge tests

\begin{tabular}{ccc}
\hline $\begin{array}{c}\text { Bacterial } \\
\text { Identity/Group }\end{array}$ & $\begin{array}{c}\text { Ifremer/Oniris } \\
\text { Strain Library } \\
\text { Code }\end{array}$ & Species \\
\hline \multirow{3}{*}{ Shewanella baltica } & MIP 2649 & S. baltica \\
& MIP 2641 & S. baltica \\
& MIP 2666 & S. baltica \\
& MIP 2520 & S. baltica \\
\hline MIP 2505 & C. maltaromaticum \\
Carnobacterium & MIP 2636 & C. maltaromaticum \\
maltaromaticum & MIP 2654 & C. maltaromaticum \\
& MIP 2504 & C. maltaromaticum \\
& MIP 2526 & C. maltaromaticum \\
Aeromonas salmonicida & MIP 2631 & C. maltaromaticum \\
\hline Vibrio sp. & MIP 2646 & A. salmonicida \\
& MIP 2657 & A. salmonicida \\
\hline "Other Gamma- & MIP 2648 & Vibrio sp. \\
Proteobacteria" & MIP 2626 & Pseudoalteromonas sp. \\
\hline
\end{tabular}


Table 2: Main odours in cooked tropical shrimp inoculated with 5 bacterial groups followed by storage under MAP at $8^{\circ} \mathrm{C}$ for 32 days.

Percentage of panellists ( $n=9)$ noting specific odour characteristics is indicated in brackets. Main odours presented were noted by at least 3 panellists.

\begin{tabular}{|c|c|c|c|c|c|c|}
\hline & Non-inoculated control & Shewanella baltica & $\begin{array}{l}\text { Carnobacterium } \\
\text { maltaromaticum }\end{array}$ & Aeromonas salmonicida & Vibrio sp. & $\begin{array}{l}\text { "Other Gamma- } \\
\text { Proteobacteria" }\end{array}$ \\
\hline \multirow{3}{*}{ Day 8} & Cabbage/sulphur (44.4) & Sour (44.4) & Sour (66.7) & Butter (77.8) & Crustacean (55.6) & Crustacean (33.3) \\
\hline & Crustacean (33.3) & Cabbage/sulphur (33.3) & Butter (33.3) & Pyrrolidine (44.4) & Sour (44.4) & Sour (33.3) \\
\hline & & Pyrrolidine (33.3) & Milky (33.3) & & Cabbage/sulphur (33.3) & Feet/cheese (33.3) \\
\hline \multirow{3}{*}{ Day 15} & Crustacean (55.6) & Cabbage/sulphur (66.7) & Sour $(66.7)$ & Pyrrolidine (44.4) & Crustacean (44.4) & Feet/cheese (55.6) \\
\hline & Rice (33.3) & Sour (44.4) & Feet/Cheese (33.3) & Amine (33.3) & Floorcloth (33.3) & Butter (33.3) \\
\hline & & Amine (33.3) & Butter (33.3) & & & \\
\hline \multirow{3}{*}{ Day 26} & Crustacean (33.3) & Cabbage/sulphur (66.7) & Sour (55.6) & Sour (44.4) & Sour (33.3) & Sour (66.7) \\
\hline & Rice (33.3) & Sour (44.4) & Feet/cheese (44.4) & Cabbage/sulphur (33.3) & Acid (33.3) & Feet/cheese (55.6) \\
\hline & Sour/fermented (33.3) & & Acid (33.3) & Butter (33.3) & & \\
\hline \multirow{3}{*}{ Day 32} & Nothing (33.3) & Sour (66.7) & Sour (77.8) & Sour $(44.4)$ & Sour (44.4) & Sour (44.4) \\
\hline & Feet/cheese (33.3) & Cabbage/sulphur (55.5) & Feet/Cheese (44.4) & Cabbage/sulphur (44.4) & Cabbage/sulphur(33.3) & Nothing (33.3) \\
\hline & Acid (33.3) & & Acid (44.4) & Amine (33.3) & Crustacean (33.3) & \\
\hline
\end{tabular}


Table 3: Specific volatile compounds identified in spoiled S. baltica-inoculated cooked tropical shrimp after 18 days of storage at $8^{\circ} \mathrm{C}$

\begin{tabular}{|c|c|c|c|c|}
\hline Volatile compound & $\begin{array}{l}\text { Non-inoculated } \\
\text { (control) } \\
\text { Day 1 } \\
\end{array}$ & $\begin{array}{c}\text { Non-inoculated } \\
\text { (control) } \\
\text { Day } 18 \\
\end{array}$ & $\begin{array}{c}\text { S. baltica } \\
\text { Day } 1\end{array}$ & $\begin{array}{l}\text { S. baltica } \\
\text { Day } 18\end{array}$ \\
\hline Alcohols & & & & \\
\hline Butanol & ND & ND & ND & $4.99 \pm 0.09$ \\
\hline 1-pentanol (amyl alcohol) & $5.48 \pm 0.16$ & $5.73 \pm 0.01$ & $5.77 \pm 0.17$ & $6.37 \pm 0.04$ \\
\hline Isoamyl alcohol & ND & ND & ND & $5.54 \pm 0.11$ \\
\hline Ethanol & $7.38 \pm 0.01$ & $7.44 \pm 0.01$ & $7.28 \pm 0.03$ & $6.86 \pm 0.23$ \\
\hline 1-penten-3-ol & $5.39 \pm 0.02$ & $6.00 \pm 0.02$ & $5.36 \pm 0.03$ & $6.14 \pm 0.14$ \\
\hline 1-hexanol & ND & ND & $\mathrm{ND}$ & $6.14 \pm 0.15$ \\
\hline $\begin{array}{l}\text { Aldehydes } \\
\text { 2-hexenal }\end{array}$ & ND & ND & ND & $5.52 \pm 0.03$ \\
\hline $\begin{array}{c}\text { Acid } \\
\text { Acetic acid }\end{array}$ & ND & ND & ND & $6.27 \pm 0.15$ \\
\hline Isovaleric acid & ND & ND & ND & $4.53 \pm 1.41$ \\
\hline Isobutyric acid & ND & ND & ND & $4.39 *$ \\
\hline $\begin{array}{c}\text { Ketones } \\
\text { 2-propanone (acetone) } \\
\text { 2-heptanone } \\
\text { 3-hydroxybutanone (acetoin) } \\
\text { 2-nonanone } \\
\text { 2-decanone }\end{array}$ & $\begin{array}{l}\text { ND } \\
\text { ND } \\
\text { ND } \\
\text { ND } \\
\text { ND }\end{array}$ & $\begin{array}{l}\text { ND } \\
\text { ND } \\
\text { ND } \\
\text { ND } \\
\text { ND }\end{array}$ & $\begin{array}{l}\text { ND } \\
\text { ND } \\
\text { ND } \\
\text { ND } \\
\text { ND }\end{array}$ & $\begin{array}{c}6.81 \pm 0.15 \\
5.34 \pm 0.13 \\
5.28 * \\
5.52 \pm 0.24 \\
4.72 *\end{array}$ \\
\hline $\begin{array}{c}\text { Other } \\
\text { Methyl mercaptan } \\
\text { Methyl-P-tert-butyl phenyl acetate } \\
\text { p-Menthane }\end{array}$ & $\begin{array}{l}5.24 \pm 0.37 \\
\text { ND } \\
\text { ND }\end{array}$ & $\begin{array}{l}\text { ND } \\
\text { ND } \\
\text { ND }\end{array}$ & $\begin{array}{l}5.04 \pm 0.18 \\
\text { ND } \\
\text { ND }\end{array}$ & $\begin{array}{l}6.34 \pm 0.10 \\
4.57 \pm 0.10 \\
5.32 \pm 0.19\end{array}$ \\
\hline
\end{tabular}

ND: Not detected

Values are averages \pm standard deviation of $\log$ (peak area/g). $n=3$

$* \mathrm{n}=1$ 


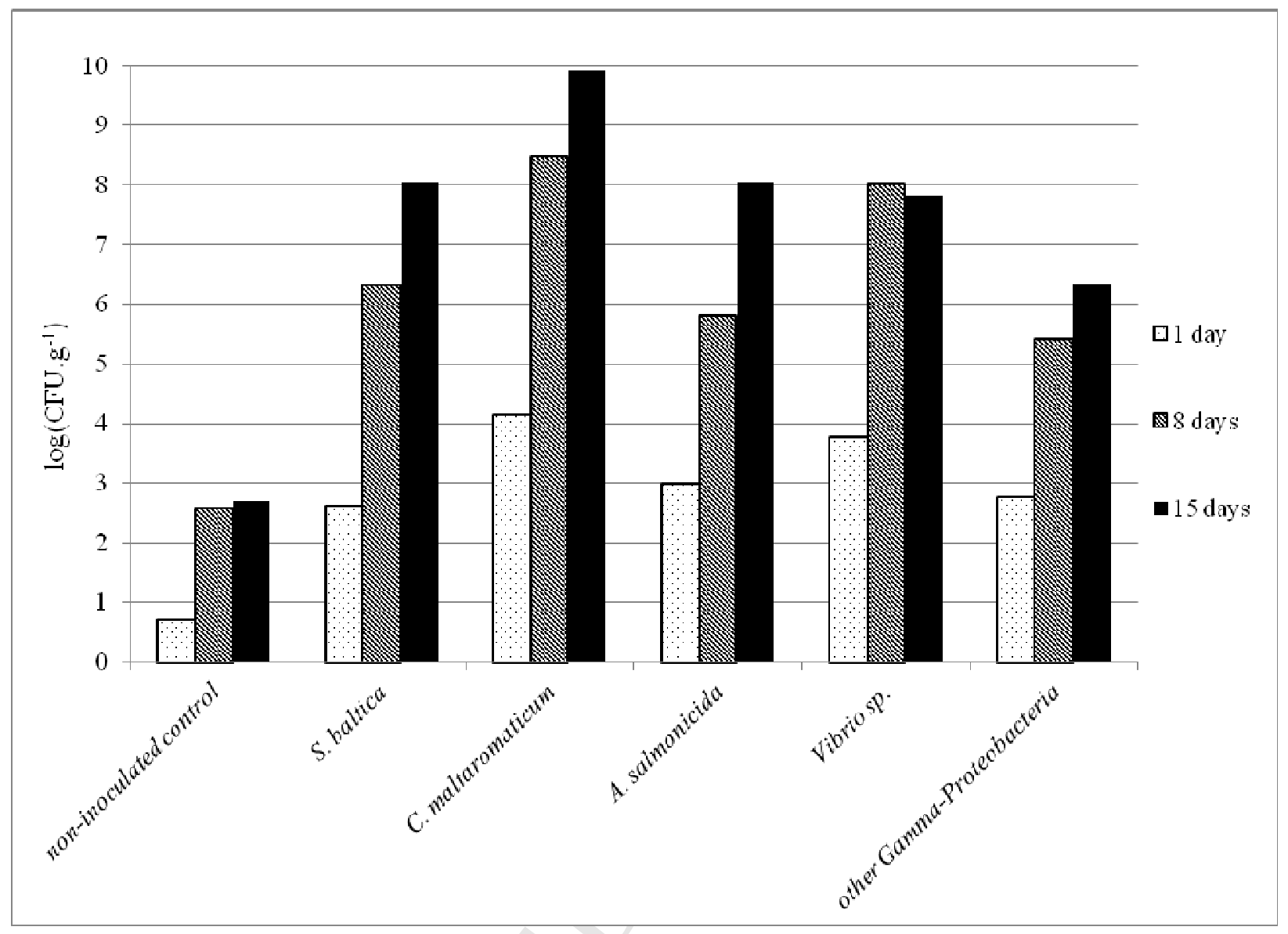




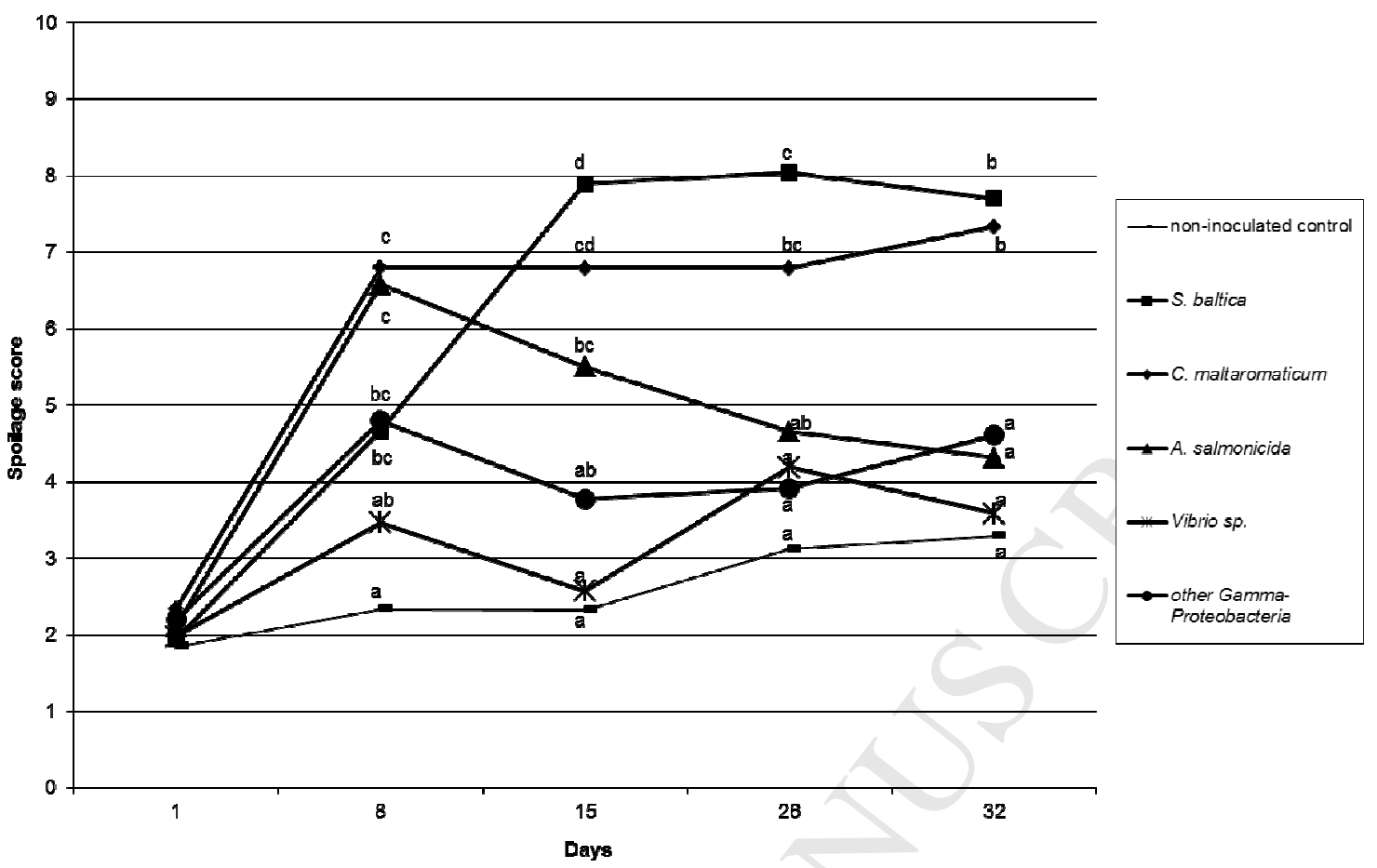




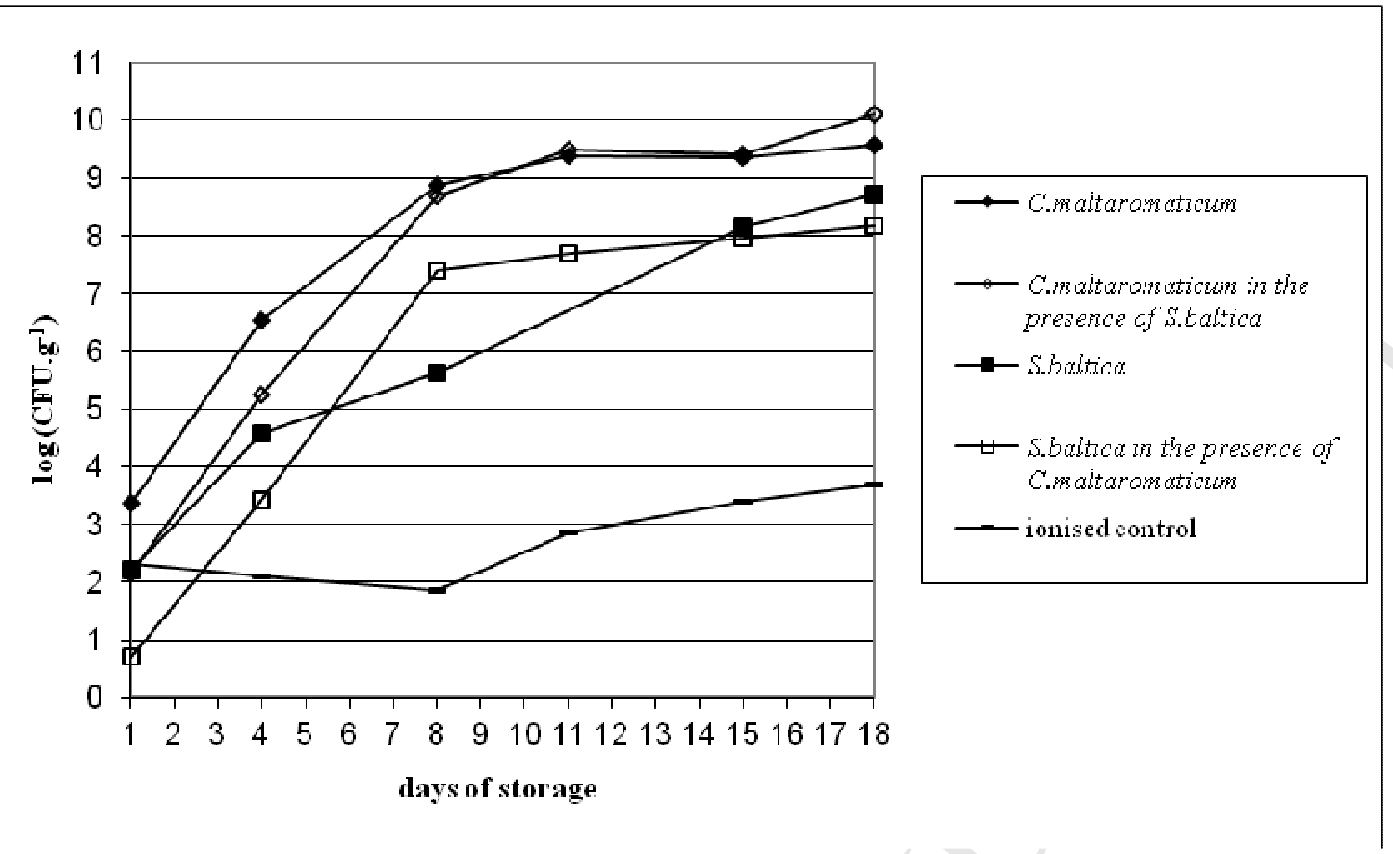




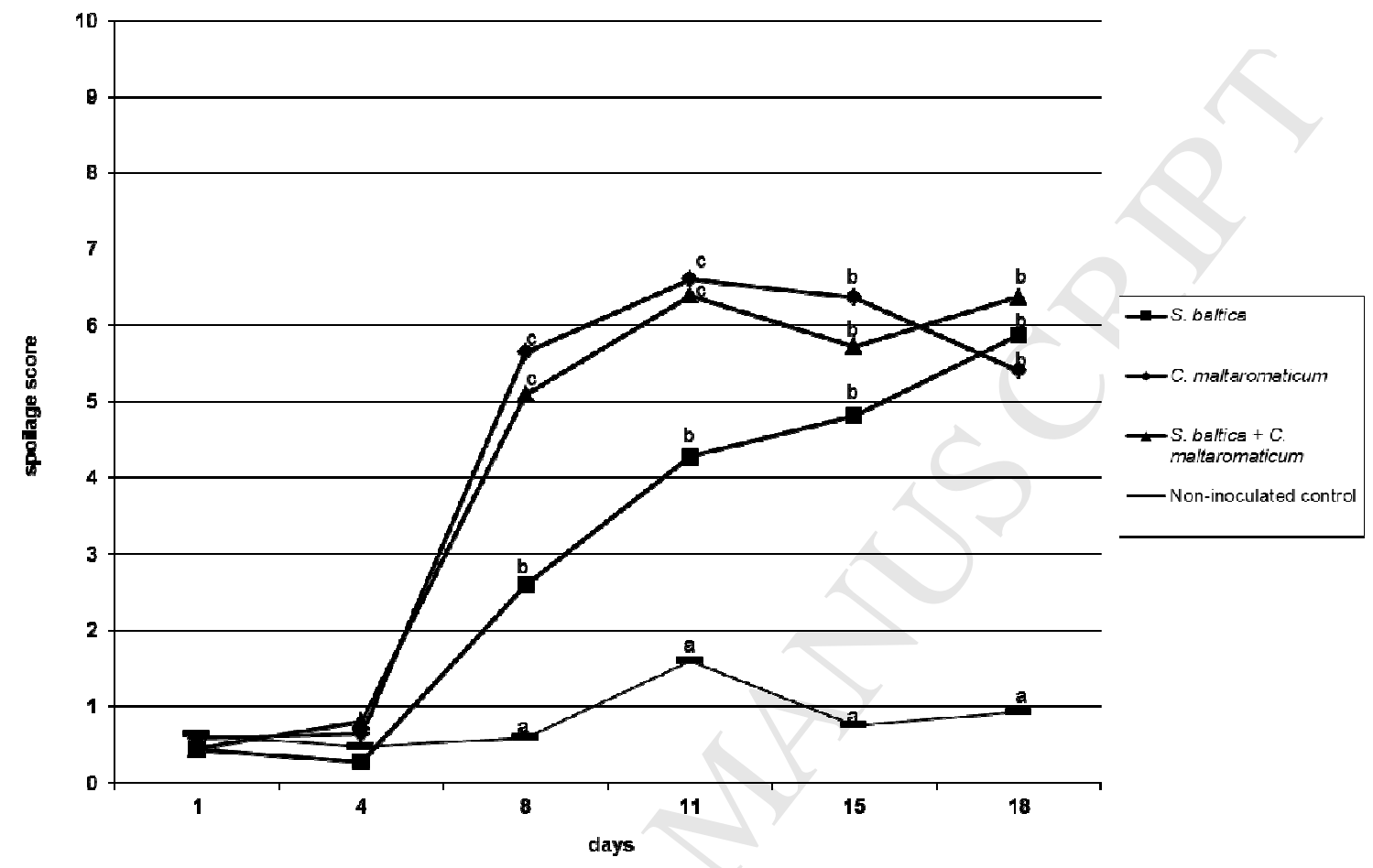




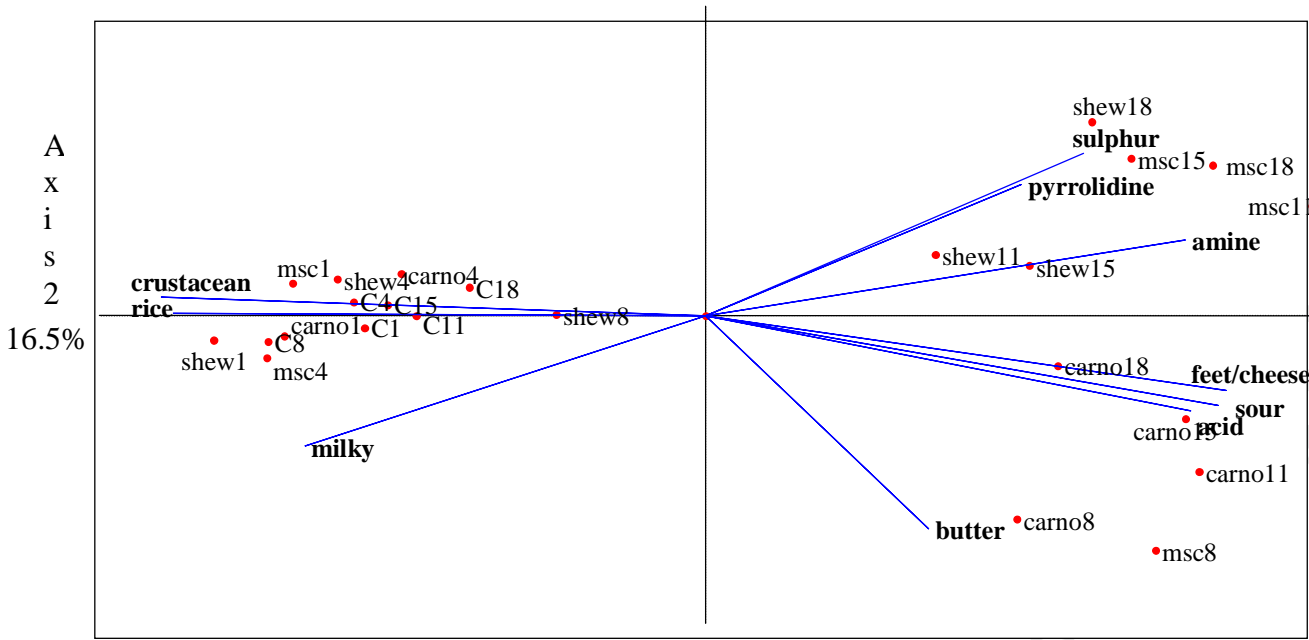

Axis $1-64.4 \%$ 


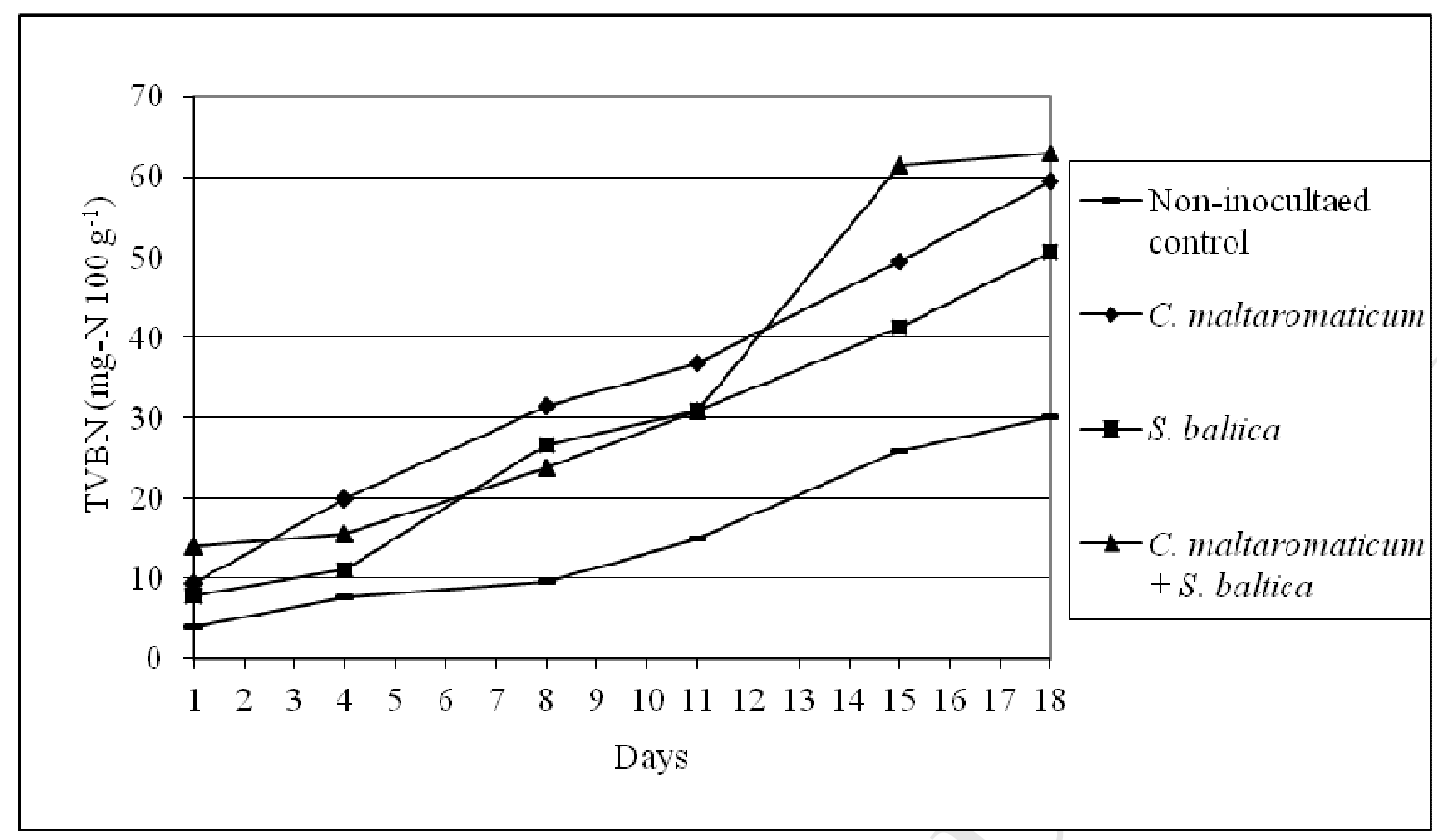



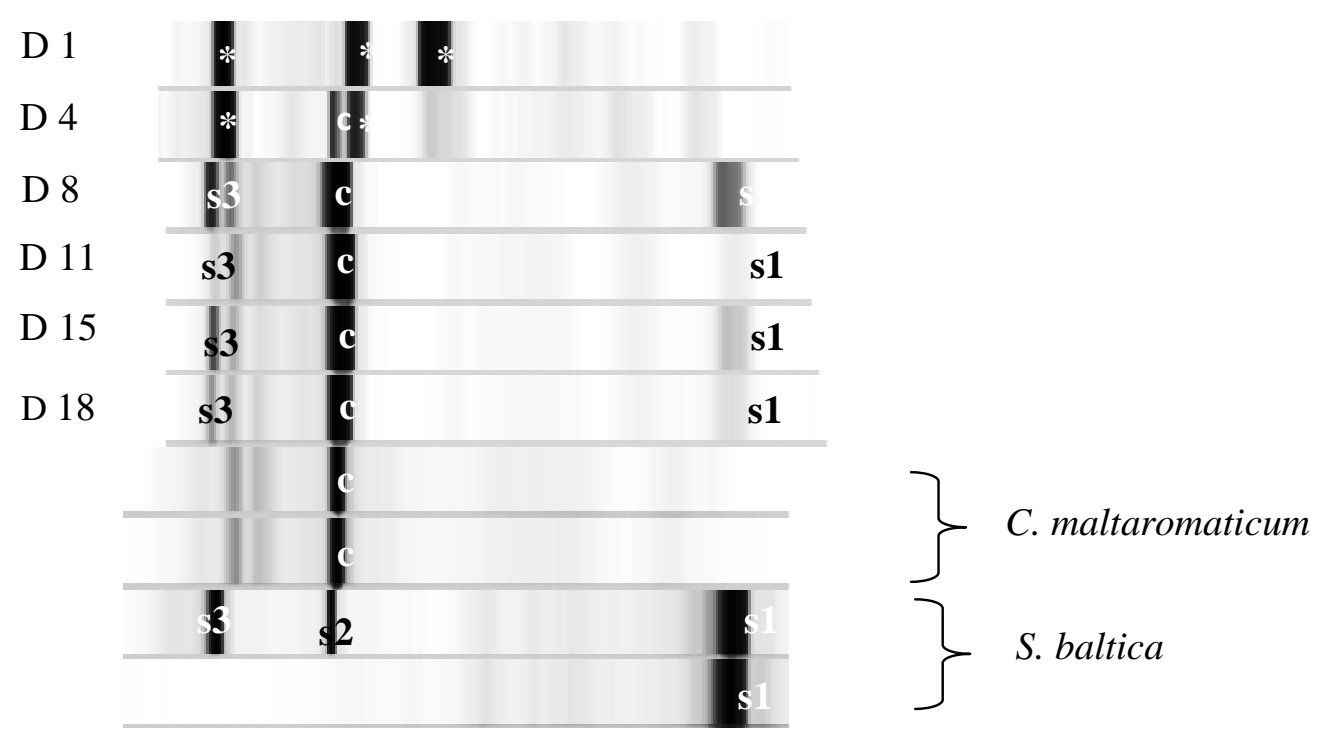